\title{
Modified Liu-Carter Compression Model for Natural Clays with Various Initial Water Contents
}

\author{
Sen Qian, Jian Shi, and Jian-wen Ding \\ Institute of Geotechnical Engineering, Southeast University, Nanjing 210096, China \\ Correspondence should be addressed to Sen Qian; qiansen@seu.edu.cn
}

Received 23 February 2016; Revised 26 April 2016; Accepted 23 May 2016

Academic Editor: Christophe Petit

Copyright (C) 2016 Sen Qian et al. This is an open access article distributed under the Creative Commons Attribution License, which permits unrestricted use, distribution, and reproduction in any medium, provided the original work is properly cited.

\begin{abstract}
The initial water content has a significant effect on the compression behaviour of reconstituted clays. This effect has to be considered in the Liu-Carter model to ensure the addition voids ratio only related to soil structure. A modified Liu-Carter compression model is proposed by introducing the empirical equations for reconstituted clays at different initial water contents into the Liu-Carter model. The proposed model is verified against the experimental results from the literature. The simulations by the proposed method are also compared with that by old method where the influence of initial water content is not considered. The results show that the predicted virgin compression curves of natural clays are similar, but the values of $b$ and $\Delta e_{\mathrm{y}}$ may be very different.
\end{abstract}

\section{Introduction}

Natural clays generally sustain a higher void ratio than the corresponding reconstituted clays at the same stress level in the compression curves [1-4]. The void ratio difference $(\Delta e)$ between natural clays and reconstituted clays at the same effective stress often decreases with increasing consolidation stress when the applied stress exceeds the consolidation yield stress [4-7]. This void ratio difference $\Delta e$, named as the additional voids ratio, is commonly attributed to the effect of soil structure that is developed during the depositional and the postdepositional processes [1-3]. The decrease of $\Delta e$ with stress level is owing to the progressive destructuring $[5,6,8]$.

Liu and Carter $[5,6]$ proposed a compression model to quantify the effect of destructuring on the additional voids ratio $\Delta e$. They assumed that $\Delta e$ is only controlled by soil structure and inversely proportional to the current effective stress during virgin compression. This model is termed as Liu-Carter compression model in this study. The formulation of this model is simple and the involved parameters have the clear physical meanings. As a consequence, it has been widely and successfully employed for constitutive modelling of structured clays [9-11].

Since the compression line of reconstituted clay is not routinely measured [3], the reference line of determining $\Delta e$ is generally estimated from the intrinsic compression line (ICL) $[6,8,9]$. Note that the determination of ICL is based on the oedometer test data on reconstituted clays at an initial water content equal to 1.25 times the liquid limits [3]. It has been well documented that the initial water contents of natural clays vary within a wide spectrum of liquid limits $[8,12,13]$. In addition, several researchers have illustrated that the initial water content significantly affects the compression behaviour of reconstituted clays [13-15]. Hong et al. [13] reported that for a given reconstituted clay the virgin compression line at a higher initial water content lies above that at a lower initial water content, as shown in Figure 1. Thus when the initial water content of the reconstituted clay is not close to the natural water content of the natural clay, the additional voids ratio $\Delta e$ will depend on not only soil structure but also the difference of initial water content. To ensure that $\Delta e$ is directly related to soil structure, the estimated reference line is therefore necessary to consider the influence of the initial water content.

In this study, a modified Liu-Carter compression model is proposed by incorporating the empirical equations proposed by Zeng et al. [15], covering a wide range of initial water contents for reconstituted clays. This modified model can take into account the effect of initial state on the compression 


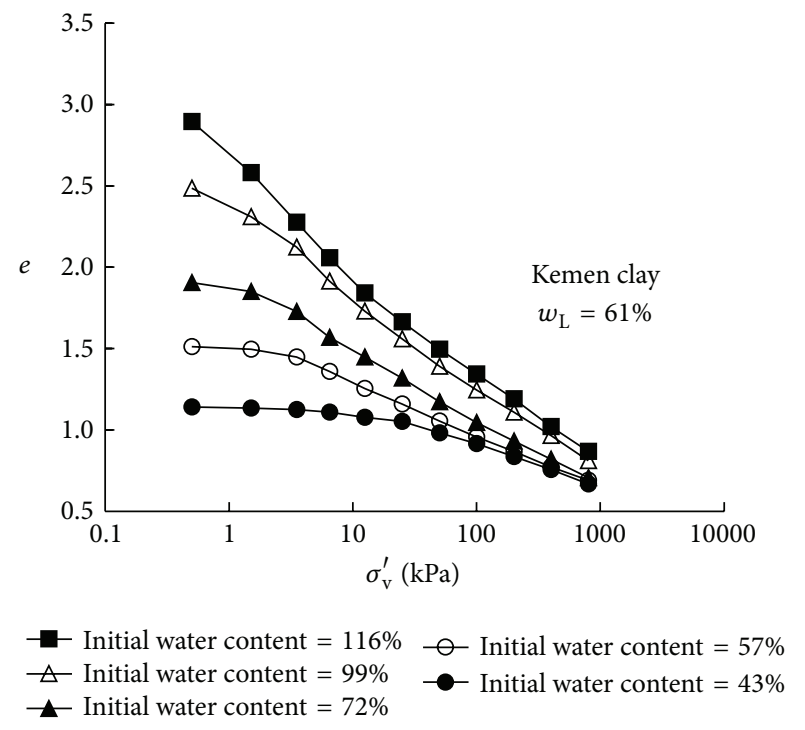

Figure 1: Typical compression curves of reconstituted clays at different initial water contents (test results from [13]).

behaviour of reconstituted clays as a reference line. The proposed model is subsequently verified against 16 oedometer tests on 8 different natural clays available from the literature.

\section{Modified Liu-Carter Compression Model}

Taking the compression curve of reconstituted clay as the reference line, Liu and Carter $[5,6]$ suggested that the void ratio of a natural clay, $e$, can be expressed in terms of the void ratio of corresponding reconstituted clay $e^{*}$ and the additional voids ratio $\Delta e$ at the same stress level, as shown in Figure 2. Through the quantification of $\Delta e$ at a given consolidation stress, the one-dimensional compression behaviour of natural clays can be evaluated as

$$
e=e^{*}+\Delta e_{\mathrm{y}}\left(\frac{\sigma_{\mathrm{vy}}^{\prime}}{\sigma_{\mathrm{v}}^{\prime}}\right)^{b} \quad \text { for } \sigma_{\mathrm{v}}^{\prime} \geq \sigma_{\mathrm{vy}}^{\prime}
$$

where $e$ and $e^{*}$ represent the void ratio of natural clay and reconstituted clay, respectively; $\sigma_{\mathrm{v}}^{\prime}$ is the effective vertical stress; $\sigma_{\text {vy }}^{\prime}$ is the effective vertical yield stress at which the natural clay begins to yield; $\Delta e_{\mathrm{y}}$ is the addition voids ratio at $\sigma_{\mathrm{vy}}^{\prime}$, owing to the original soil structure (Figure 2). $b$ is destructuring index that is a constant parameter for quantifying the rate of destructuring. The more rapidly the destructuring develops, the higher the value of $b$ is. Its value depends on soil type and soil structure [9].

In the absence of the laboratory compression curve for corresponding reconstituted clay, ICL proposed by Burland $[3]$ is often used as the reference line $[6,8,9]$. ICL is obtained by using the void index $\left(I_{\mathrm{v}}\right)$ to correlate the compression curves of reconstituted clays with initial water contents of about 1.25 times the liquid limits. Based on the definition of

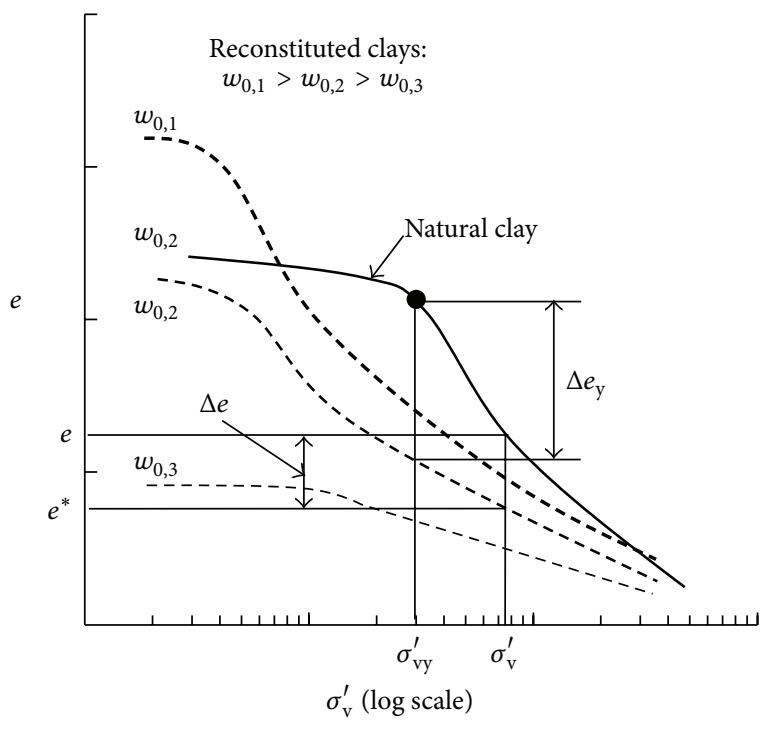

FIgURE 2: Idealization of the compression behaviour of natural clay and reconstituted clays at different initial water contents (after Bian et al. [16]).

$I_{\mathrm{v}}$, the virgin compression curve of reconstituted clays can be expressed as [3]

$$
e^{*}=e_{100}^{*}+C_{c}^{*} \times I_{\mathrm{v}}
$$

where $e_{100}^{*}$ is the void ratio of reconstituted clays at the effective vertical stress of $100 \mathrm{kPa}$; $C_{c}^{*}$ is termed the intrinsic compression index. In $I_{\mathrm{v}}-\log \sigma_{\mathrm{v}}^{\prime}$ space, ICL can be described by the following equation:

$$
I_{\mathrm{v}}=2.45-1.285 \log \sigma_{\mathrm{v}}^{\prime}+0.015\left(\log \sigma_{\mathrm{v}}^{\prime}\right)^{3} .
$$

Burland [3] also showed that components $e_{100}^{*}$ and $C_{c}^{*}$ in (2) can be estimated by the following two empirical equations:

$$
\begin{aligned}
e_{100}^{*} & =0.109+0.679 e_{\mathrm{L}}-0.089 e_{\mathrm{L}}^{2}+0.016 e_{\mathrm{L}}^{3} \\
C_{c}^{*} & =0.256 e_{\mathrm{L}}-0.04,
\end{aligned}
$$

where $e_{\mathrm{L}}$ is the void ratio at the liquid limit, and it can be evaluated directly using the equation $e_{\mathrm{L}}=G_{\mathrm{s}} \times w_{\mathrm{L}}\left(G_{\mathrm{s}}\right.$ is the density of soil particle; $w_{\mathrm{L}}$ is the liquid limit). Therefore, when $e_{\mathrm{L}}$ ranges from 0.6 to 4.5 and the initial void ratio $e_{0}=1.25 e_{\mathrm{L}}$, the virgin compression curve of reconstituted clays can be estimated by $G_{\mathrm{s}}$ and $w_{\mathrm{L}}$.

However, the initial water contents of natural clays are not always around 1.25 times the liquid limits [8, 12, 13], and the intrinsic compression curves or intrinsic compression parameters for reconstituted clays may be prominently affected by initial water contents (Figure 1) [13-15]. Hong et al. [13] illustrated that the virgin compression lines of various reconstituted clays with the initial water content at $0.7-2.0$ times the liquid limits can also be normalized by the void index $I_{\mathrm{v}}$. The normalized curve can be represented by 
TABLE 1: Details of soil samples and model parameters.

\begin{tabular}{|c|c|c|c|c|c|c|c|c|}
\hline Soils & $G_{\mathrm{s}}\left(\mathrm{g} \cdot \mathrm{cm}^{-3}\right)$ & $w_{\mathrm{L}}(\%)$ & $e_{0}$ & $e_{0} / e_{\mathrm{L}}$ & $\sigma_{\mathrm{vy}}^{\prime}(\mathrm{kPa})$ & $\Delta e_{\mathrm{y}}$ & $b$ & Reference \\
\hline Singapore clay & 2.74 & 84 & 1.59 & 0.69 & 218 & 0.50 & 0.54 & Low et al. [8] \\
\hline Gulf of Guinea clay & 2.65 & 118 & 3.28 & 1.05 & 98 & 1.17 & 0.55 & Hattab et al. [17] \\
\hline Lianyungang clay & 2.73 & 53 & 1.79 & 1.24 & 69 & 0.61 & 0.60 & Deng et al. [18] \\
\hline Jangyu clay & 2.71 & 60 & 2.35 & 1.45 & 60 & 0.97 & 0.44 & Chung et al. [19] \\
\hline Undisturbed Ariake clay & 2.66 & 127 & 4.30 & 1.27 & 38 & 1.15 & 0.30 & Liu and Hong [20] \\
\hline Disturbed Ariake clay & 2.66 & 127 & 4.30 & 1.27 & 29 & 1.27 & 0.26 & Liu and Hong [20] \\
\hline Shanghai clay & 2.70 & 45 & 1.15 & 0.94 & 160 & 0.31 & 0.24 & Li et al. [21] \\
\hline Batiscan clay & 2.67 & 43 & 2.13 & 1.85 & 117 & 1.15 & 1.05 & Leroueil et al. [22] \\
\hline \multicolumn{9}{|l|}{ Wenzhou clay } \\
\hline $5 \mathrm{~m}$ & 2.70 & 65 & 1.91 & 1.05 & 61 & 0.60 & 0.53 & \multirow{8}{*}{ Bian [23] } \\
\hline $7.5 \mathrm{~m}$ & 2.73 & 70 & 1.94 & 1.01 & 58 & 0.52 & 0.41 & \\
\hline $10 \mathrm{~m}$ & 2.71 & 69 & 1.90 & 1.02 & 80 & 0.58 & 0.53 & \\
\hline $12.5 \mathrm{~m}$ & 2.71 & 73 & 2.01 & 1.02 & 92 & 0.74 & 0.56 & \\
\hline $15 \mathrm{~m}$ & 2.70 & 76 & 1.84 & 0.90 & 100 & 0.53 & 0.85 & \\
\hline $17.5 \mathrm{~m}$ & 2.71 & 74 & 1.73 & 0.87 & 148 & 0.54 & 0.42 & \\
\hline $20 \mathrm{~m}$ & 2.71 & 65 & 1.60 & 0.91 & 138 & 0.55 & 0.57 & \\
\hline $22.5 \mathrm{~m}$ & 2.73 & 67 & 1.42 & 0.78 & 156 & 0.37 & 0.79 & \\
\hline
\end{tabular}

an extended intrinsic compression line (EICL), which is expressed as [13]

$$
I_{\mathrm{v}}=3.0-1.87 \log \sigma_{\mathrm{v}}^{\prime}+0.179\left(\log \sigma_{\mathrm{v}}^{\prime}\right)^{2} .
$$

Based on this intrinsic concept, new empirical correlations of $e_{100}^{*}$ and $C_{c}^{*}$ were proposed by Zeng et al. [15]:

$$
\begin{aligned}
e_{100}^{*} & =0.357+0.171 e_{0}+0.223 e_{\mathrm{L}} \\
C_{c}^{*} & =-0.069+0.109 e_{0}+0.152 e_{\mathrm{L}} .
\end{aligned}
$$

It should be noted that (6) are based on the test data of various reconstituted clays with $e_{\mathrm{L}}$ in the range between 0.76 and 2.7 and $e_{0} / e_{\mathrm{L}}$ in the range between 0.7 and 2.2. Zeng et al. [15] also recommended that for the reconstituted clays within an extended range of $e_{\mathrm{L}}$ from 0.66 to 5.72 the intrinsic parameters can be estimated by following relationships with a possible reduction of accuracy:

$$
\begin{aligned}
e_{100}^{*}= & 0.223+0.261 e_{0}+0.282 e_{\mathrm{L}}-0.018 e_{0}^{2}-0.05 e_{\mathrm{L}}^{2} \\
& +0.015 e_{\mathrm{L}}^{3} \\
C_{c}^{*}= & -0.064+0.153 e_{0}+0.11 e_{\mathrm{L}}-0.006 e_{0}^{2} .
\end{aligned}
$$

Knowing three parameters $G_{\mathrm{s}}, w_{\mathrm{L}}$, and $e_{0}$, the compression line of reconstituted clays could be simulated by combining (2) and (5). $e_{100}^{*}$ and $C_{c}^{*}$ can be evaluated by (6) or (7). Using this simulated compression curve as the new reference line in the Liu-Carter model, a modified Liu-Carter compression model is proposed:

$$
e=e_{100}^{*}+C_{c}^{*} \times I_{\mathrm{v}}+\Delta e_{\mathrm{y}}\left(\frac{\sigma_{\mathrm{vy}}^{\prime}}{\sigma_{\mathrm{v}}^{\prime}}\right)^{b} \text { for } \sigma_{\mathrm{v}}^{\prime} \geq \sigma_{\mathrm{vy}}^{\prime},
$$

where $I_{\mathrm{v}}, e_{100}^{*}$, and $C_{c}^{*}$ are determined by corresponding equations (5)-(7). It is showed that this modified Liu-Carter model has six basic parameters $G_{s}, w_{\mathrm{L}}, e_{0}, \sigma_{\mathrm{vy}}^{\prime}, \Delta e_{\mathrm{y}}$, and $b$. The first three parameters are physical parameters, and the last three parameters can be obtained from the laboratory consolidation tests on natural clays. The virgin compression behaviour of natural clays with different initial states could be described using this modified Liu-Carter compression model.

\section{Validation of Modified Liu-Carter Model}

To validate the modified Liu-Carter compression model, the results of 16 oedometer tests on 8 types of natural clays with different initial water contents are compiled from the literature, as shown in Table 1. Values of all parameters needed for simulation are also summarized in Table 1 . The void ratio at the liquid limit $e_{\mathrm{L}}$ can be simply obtained from $G_{\mathrm{s}}$ and $w_{\mathrm{L}}$. The value of $\sigma_{\mathrm{vy}}^{\prime}$ is identified directly from the measured compression curves using the method of Liu and Carter [6], as shown in Figure 2. The additional voids ratio at yield stress $\Delta e_{\mathrm{y}}$ is determined by comparing the measured compression curve with the predicted reference line suggested by Zeng et al. [15]. The destructuring index $b$ is evaluated by best fitting equation (8) with the measured compression data of natural clays.

As listed in Table 1, the samples are investigated over a wide spectrum of liquid limits (43-127\%) and initial state $e_{0} / e_{\mathrm{L}}(0.69-1.85)$. And it can be found that except Gulf of Guinea clay and Ariake clay, $e_{\mathrm{L}}$ value is within 0.76 to 2.7. According to the suggestion of Zeng et al. [15], $e_{100}^{*}$ and $C_{c}^{*}$ in (8) for Gulf of Guinea clay and Ariake clay should be estimated by using (7), while for other clays equations in (6) should be employed. The comparisons between the simulations and the measurements of the virgin compression curves are shown in Figures 3-7. The initial yield point of 


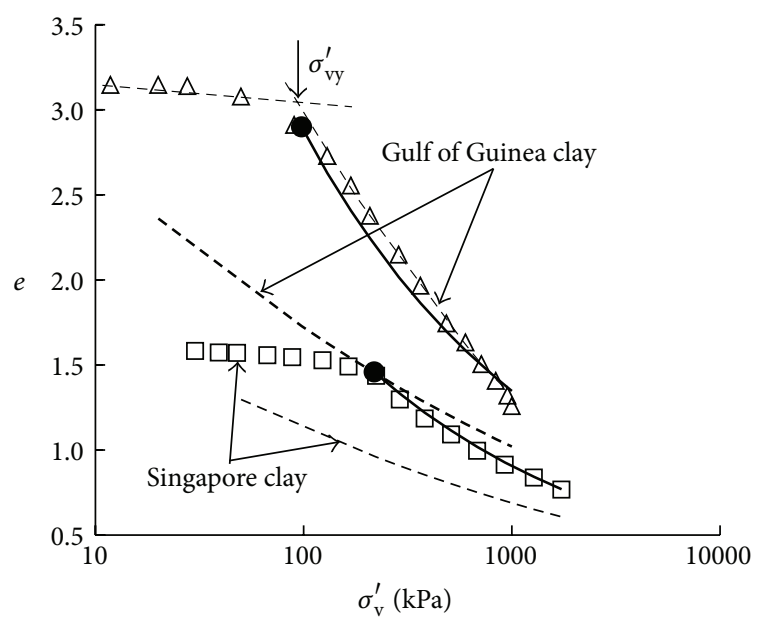

FIGURE 3: Comparison between simulated and experimental results for Singapore clay and Gulf of Guinea clay based on test data reported by Low et al. [8] and Hattab et al. [17], respectively.

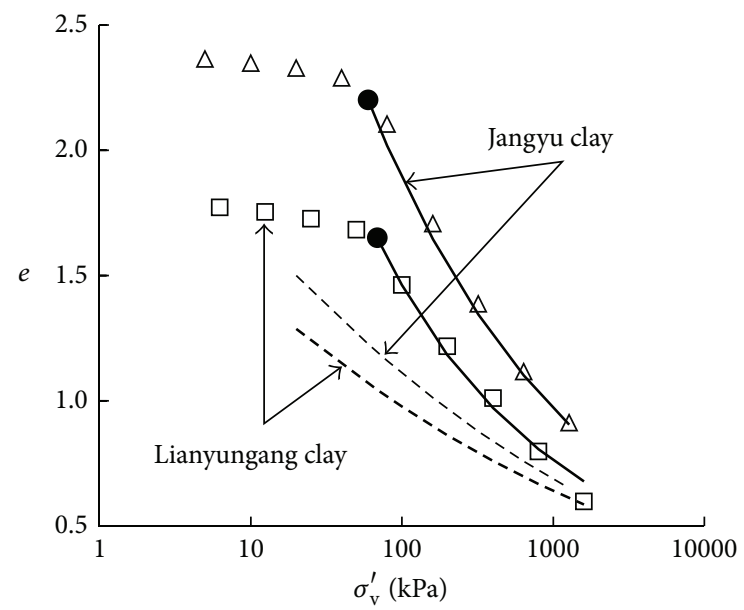

FIGURE 4: Comparison between simulated and experimental results for Lianyungang clay and Jangyu clay based on test data reported by Deng et al. [18] and Chung et al. [19], respectively.

each sample is represented by a solid circle. The experimental data and simulated compression curves for natural clays are indicated by open dots and thick solid lines, respectively. The predicted reference lines are showed as broken lines. It should be pointed out that the compression behaviour of natural clays prior to yielding was not investigated here.

Figures 3-7 show that all the simulated virgin compression curves agree well with the experimental data of the natural clays at different initial states. It demonstrates that the modified Liu-Carter compression model is capable of quantifying the influence of soil structure on the virgin compression of natural clays.

Furthermore, for the purpose of model application, some discussions on the key parameters $\Delta e_{\mathrm{y}}$ and $b$ are necessary. The addition voids ratio $\Delta e_{\mathrm{y}}$ owing to the influence of original soil structure should be closely correlated with the stress sensitivity $S_{\sigma \mathrm{y}}\left(=\sigma_{\mathrm{vy}}^{\prime} / \sigma_{\mathrm{ye}}^{*}\right)$, where $\sigma_{\mathrm{ye}}^{*}$ is the equivalent

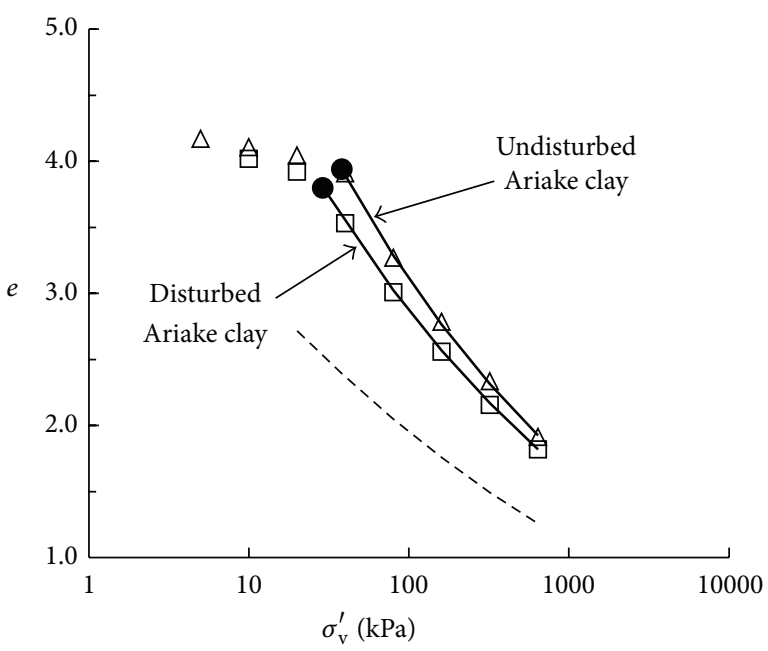

FIGURE 5: Comparison between simulated and experimental results for undisturbed and disturbed Ariake clay based on test data reported by Liu and Hong [20].

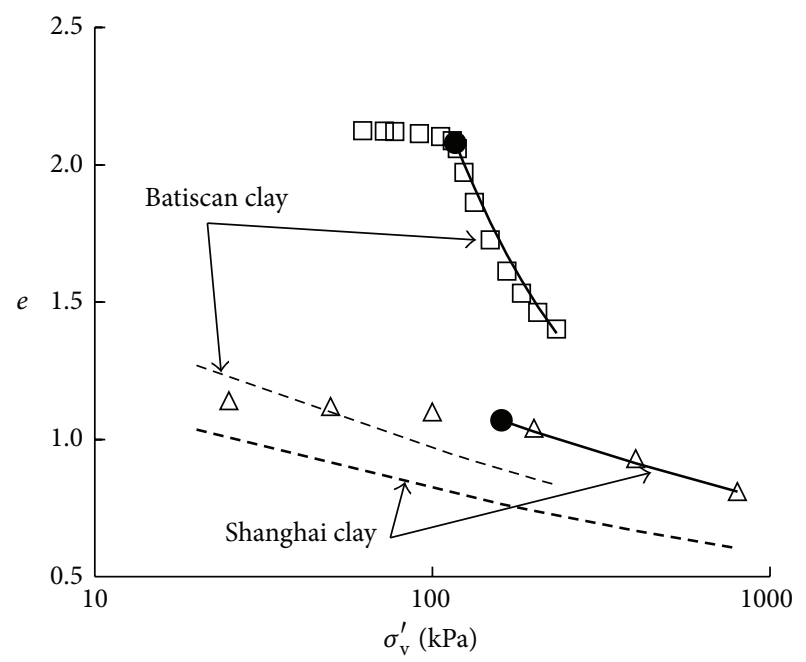

FIGURE 6: Comparison between simulated and experimental results for Shanghai clay and Batiscan clay based on test data reported by $\mathrm{Li}$ et al. [21] and Leroueil et al. [22], respectively.

stress on the intrinsic compression line at the void ratio of natural clay under $\sigma_{\mathrm{vy}}^{\prime}$ [8]. Low et al. [8] suggested that if an experimental compression curve is unavailable, $S_{\sigma 0}$ $\left(=\sigma_{\mathrm{vy}}^{\prime} / \sigma_{\mathrm{v} 0 e}^{*}\right)$ instead of $S_{\sigma \mathrm{y}}$ can be used to estimate the value of $\Delta e_{\mathrm{y}}$, where $\sigma_{\mathrm{v} 0 e}^{*}$ is the equivalent stress on the intrinsic compression line at the initial void ratio. But the ratio between $\Delta e_{\mathrm{y}}$ and $\ln S_{\sigma 0}$ is not always a constant for different clays [8] (Figure 8). Similarly, a different parameter $\Delta I_{\mathrm{vy}}$ $\left(=\Delta e_{\mathrm{y}} / C_{c}^{*}\right)$ could be used here, which is the additional void index at $\sigma_{\mathrm{vy}}^{\prime}$. Figure 9 shows the relationship between $\Delta I_{\mathrm{vy}}$ and $\ln S_{\sigma 0}$ for the soils in Table 1, and regression equation (9) is 


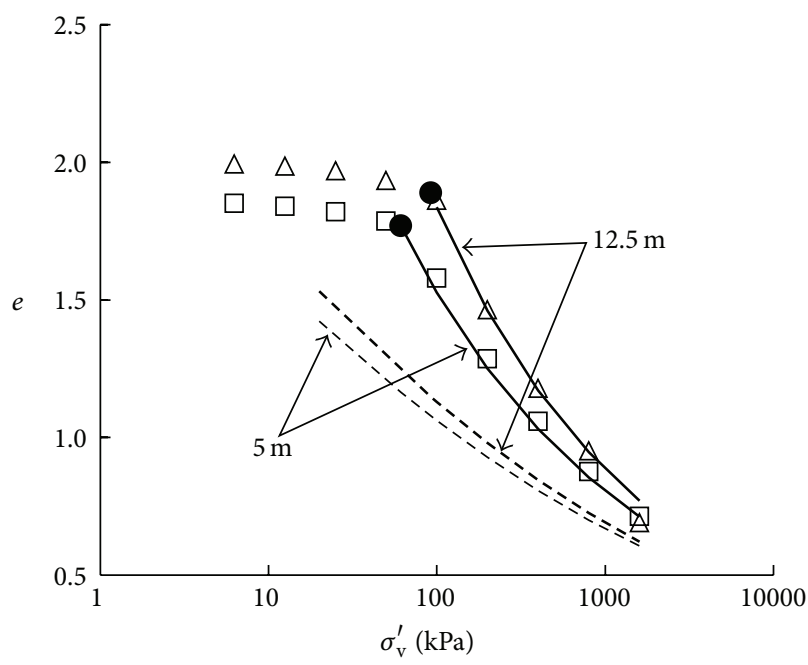

(a)

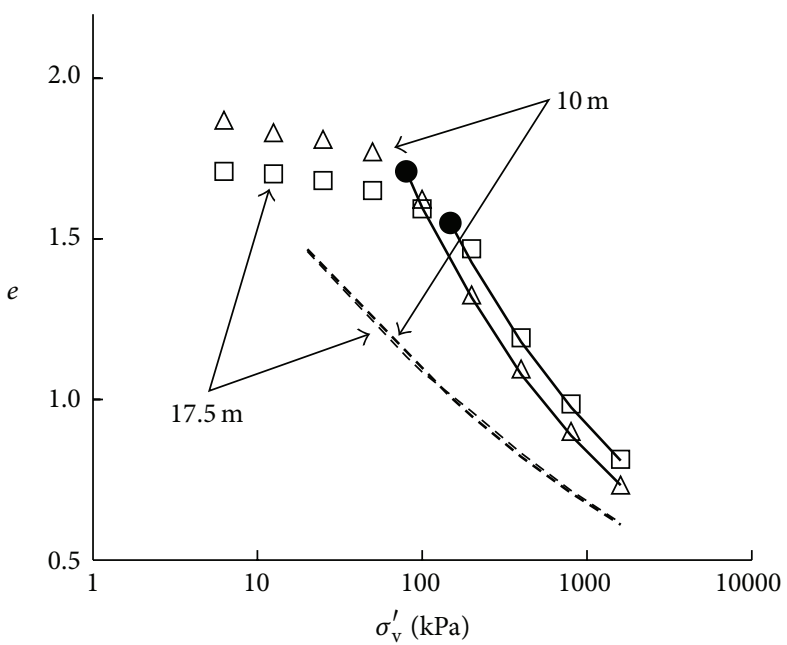

(c)

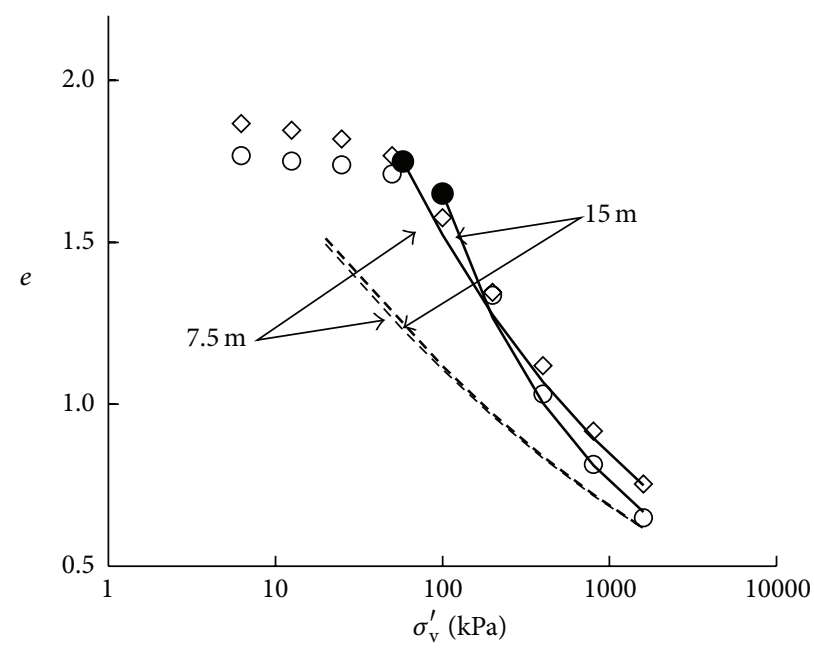

(b)

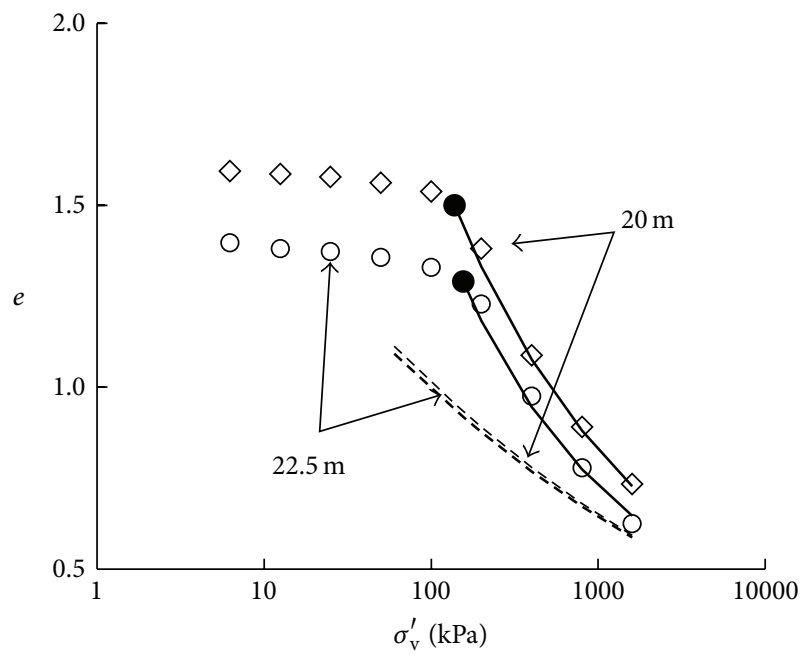

(d)

FIGURE 7: Comparison between simulated and experimental results for Wenzhou clay based on test data reported by Bian [23]: (a) $5 \mathrm{~m}$ and $12.5 \mathrm{~m}$; (b) $7.5 \mathrm{~m}$ and $15 \mathrm{~m}$; (c) $10 \mathrm{~m}$ and $17.5 \mathrm{~m}$; (d) $20 \mathrm{~m}$ and $22.5 \mathrm{~m}$.

obtained with $R^{2}=0.80$. Hence, when the experimental data is unavailable, the parameter $\Delta e_{\mathrm{y}}$ could be estimated via (10):

$$
\begin{aligned}
\Delta I_{\mathrm{vy}} & =0.52 \ln S_{\sigma 0} \\
\Delta e_{\mathrm{y}} & =0.52 C_{c}^{*} \ln \left(\frac{\sigma_{\mathrm{vy}}^{\prime}}{\sigma_{\mathrm{v} 0 e}^{*}}\right) .
\end{aligned}
$$

Currently, it is not possible to perform a systematic and detailed study on the prediction of $b$ due to the limited amount of experimental data $[6,8]$. But some changes in the $b$ value can be generalized. The $b$ value for these natural clays is between 0.24 and 1.05 , which is comparable with that reported by Liu and Carter [6] for natural soft clays (ranging from 0.38 to 1.32). As seen in Table 1, the $b$ value of undisturbed Ariake clay is higher than that of disturbed Ariake clay (Figure 5). This implies that the rate of destructuring can be reduced by disturbance. Liu and Carter
[6] hypothesized that for clay samples of a given mineralogy and with similar geological stress history but at different depths, $b$ may be mainly dependent on the liquidity index. Similarly, for natural Wenzhou clay at different depths taken from the same location, $b$ tends to decrease with the increase of the value of $e_{0} / e_{\mathrm{L}}$, as shown in Figure 10.

\section{Discussion on the Effect of the Initial State}

In order to investigate the influence of initial state on the simulations, the predicted curves and parameters $b$ and $\Delta e_{\mathrm{y}}$ in the modified Liu-Carter model are compared with the ones determined by (8) but with $I_{\mathrm{v}}, e_{100}^{*}$, and $C_{c}^{*}$ evaluated via (3)-(4), where the influence of initial water contents is not considered. Singapore clay $\left(e_{0} / e_{\mathrm{L}}=0.69\right)$, Lianyungang clay $\left(e_{0} / e_{\mathrm{L}}=1.24\right)$, and Batiscan clay $\left(e_{0} / e_{\mathrm{L}}=1.85\right)$ are chosen to be analyzed in this part because that they cover the whole range of initial water contents listed in Table 1. 


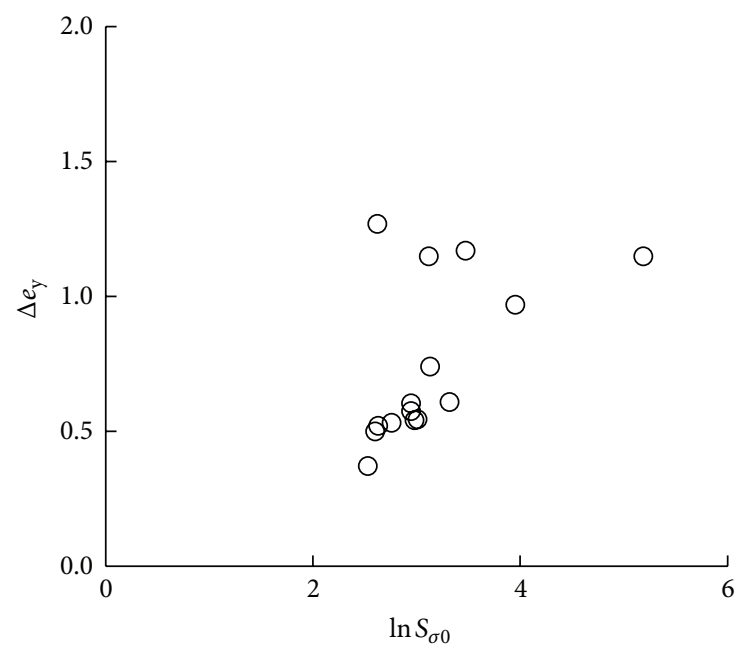

FIgURE 8: The relationship between $\Delta e_{\mathrm{y}}$ and $\ln S_{\sigma 0}$ for the clays in Table 1.

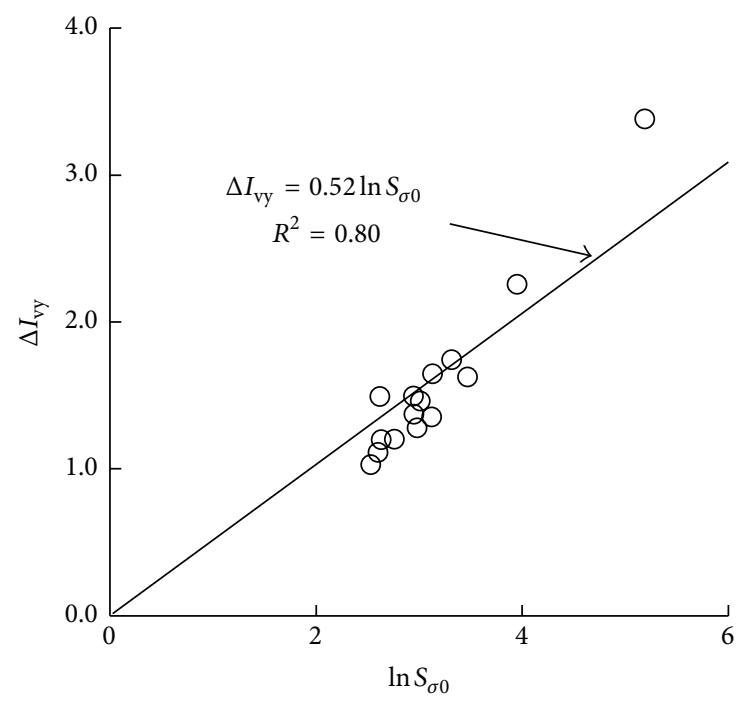

Figure 9: The relationship between $\Delta I_{\mathrm{vy}}$ and $\ln S_{\sigma 0}$ for the clays in Table 1.

The comparison results of predicted compression curves are summarized in Figure 11. The predicted compression curves of natural clays and reconstituted clays without considering the initial state are represented by thin solid lines and thin broken lines, respectively. The corresponding ones for the modified Liu-Carter model are represented by thick solid lines and thick broken lines. It can be seen from Figure 11 that the predicted curves of natural clays without considering the initial state are almost identical to that considering the initial state, and they both agree well with the experimental data. It means that the initial states may have no noticeable effect on the predicted compression curves of natural clays. But as seen from Figures 11(a) and 11(c), the predicted compression lines of reconstituted Singapore clay and reconstituted Batiscan clay $\left(e_{0} / e_{\mathrm{L}}\right.$ is not around 1.25$)$ differ greatly in locations.

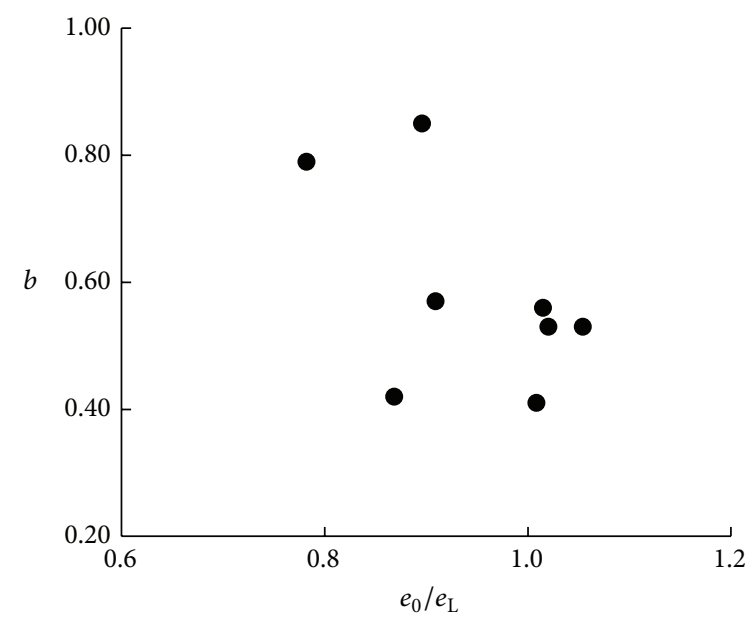

Figure 10: The values of $b$ versus $e_{0} / e_{\mathrm{L}}$ for Wenzhou clay at different depths.

It is expected that the different locations of the reference line would cause great difference in the value of $b$ and $\Delta e_{y}$.

Figures 12(a) and 12(b) show the comparison results of the key parameters $b$ and $\Delta e_{y}$. For Lianyungang clay with $e_{0}$ equal to $1.24 e_{\mathrm{L}}$, the values of $b$ and $\Delta e_{\mathrm{y}}$ obtained from two different methods are almost the same with a little difference less than 5 percent. The reason is that the reference lines estimated nearly coincide (Figure 11(b)). However, for Singapore clay with $e_{0}$ equal to $0.69 e_{\mathrm{L}}$, compared to the corresponding values for the modified Liu-Carter model, $b$ and $\Delta e_{\mathrm{y}}$ without considering the initial state are 67 percent higher and 48 percent lower, respectively. For Batiscan clay with $e_{0}$ equal to $1.85 e_{\mathrm{L}}, b$ and $\Delta e_{\mathrm{y}}$ without considering the initial state are 11 percent lower and 14 percent higher than the ones for the modified LiuCarter model. This observation indicates that when $e_{0} / e_{\mathrm{L}}$ is not around 1.25, using the estimated reference line without considering the initial state may lead to a noticeable error in the determination of $b$ and $\Delta e_{y}$. In other words, it is essential for parameters $b$ and $\Delta e_{\mathrm{y}}$ of different natural clays to consider the influence of initial state. Thus, the quantification of destructuring by the modified Liu-Carter model can be successful for various natural clays at a wide range of initial water content.

\section{Conclusions}

Based on the modelling, validation, and discussion presented in this study, the following conclusions can be drawn:

(1) By introducing the empirical equations for reconstituted clays proposed by Zeng et al. [15] to LiuCarter compression model, a modified Liu-Carter model is proposed to consider the effect of initial state. The mathematical formulation is $e=e_{100}^{*}+$ $C_{c}^{*} \times I_{\mathrm{v}}+\Delta e_{\mathrm{y}}\left(\sigma_{\mathrm{vy}}^{\prime} / \sigma_{\mathrm{v}}^{\prime}\right)^{b}$, for $\sigma_{\mathrm{v}}^{\prime} \geq \sigma_{\mathrm{vy}}^{\prime}$, where $I_{\mathrm{v}}=$ $3.0-1.87 \log \sigma_{\mathrm{v}}^{\prime}+0.179\left(\log \sigma_{\mathrm{v}}^{\prime}\right)^{2}$, and $e_{100}^{*}$ and $C_{c}^{*}$ are determined by three physical parameters $G_{s}, w_{\mathrm{L}}$, and $e_{0}$. 


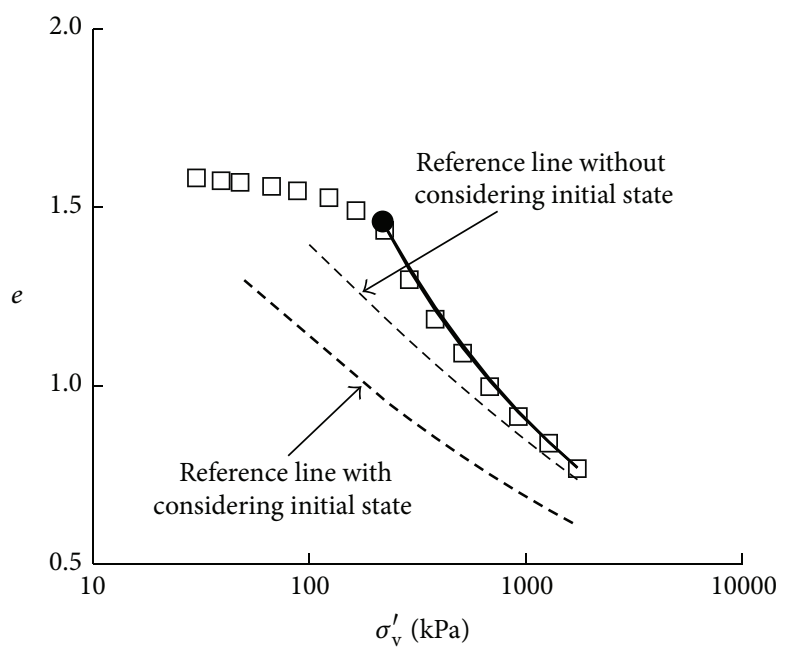

(a)

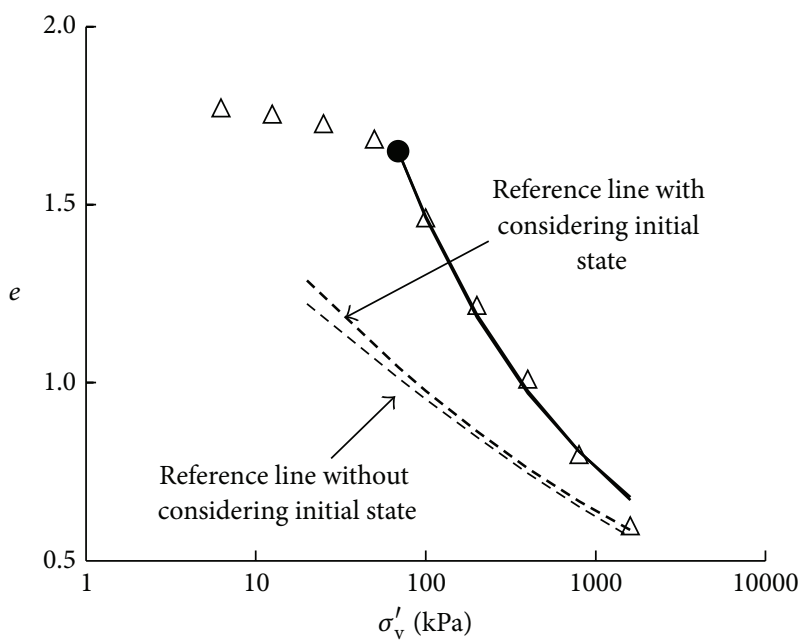

(b)

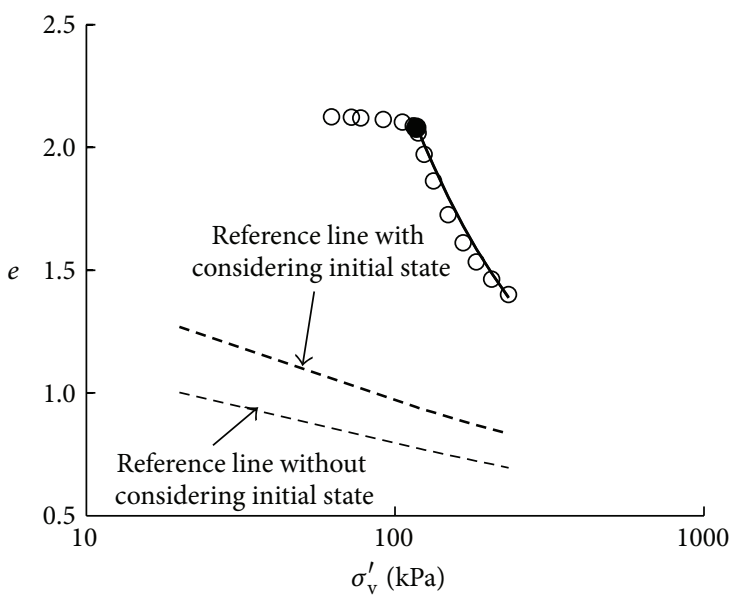

(c)

FIGURE 11: The influence of initial state on simulated curves: (a) Singapore clay, $e_{0} / e_{\mathrm{L}}=0.69$; (b) Lianyungang clay, $e_{0} / e_{\mathrm{L}}=1.24 ;(\mathrm{c})$ Batiscan clay, $e_{0} / e_{\mathrm{L}}=1.85$.

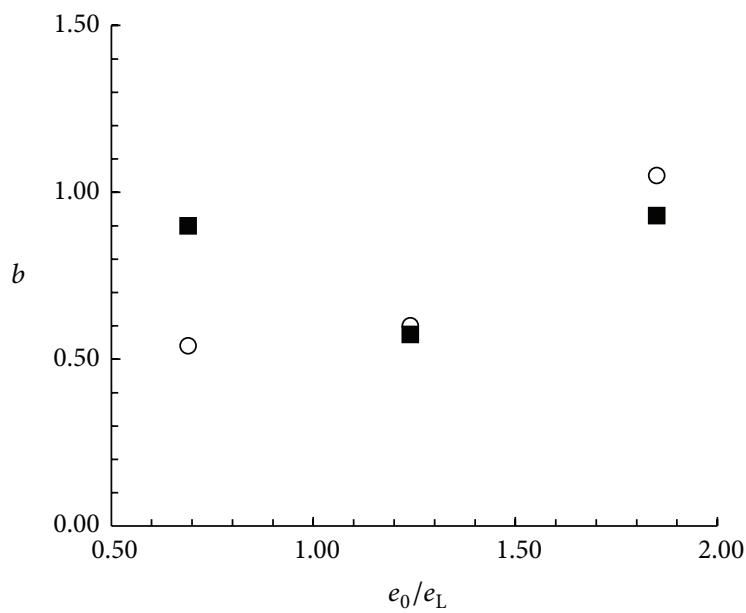

With considering initial state

- Without considering initial state

(a)

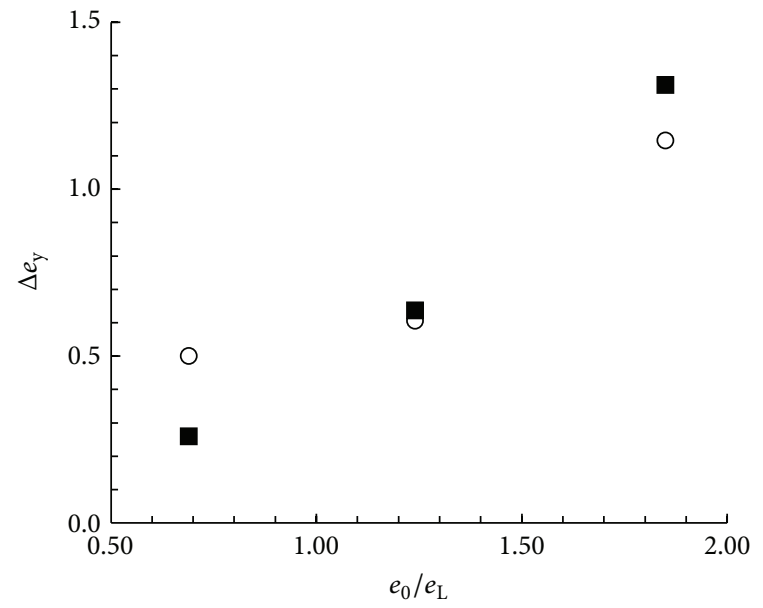

With considering initial state

- Without considering initial state

(b)

FIgURE 12: The influence of initial state on the model parameters: (a) $b$ versus $e_{0} / e_{\mathrm{L}}$; (b) $\Delta e_{\mathrm{y}}$ versus $e_{0} / e_{\mathrm{L}}$. 
(2) The numerous comparisons of simulations and experimental results show that the modified Liu-Carter model could quantify successfully the virgin compression behaviour of natural clays over a wide spectrum of initial water content.

(3) Compared to the corresponding values of $b$ and $\Delta e_{\mathrm{y}}$ for the modified Liu-Carter model, the values of $b$ and $\Delta e_{\mathrm{y}}$ without considering the influence of initial water contents will be higher and lower, respectively, when $e_{0} / e_{\mathrm{L}}$ is less than 1.25. On the contrary, the values of $b$ and $\Delta e_{\mathrm{y}}$ will be lower and higher, respectively, when $e_{0} / e_{\mathrm{L}}$ is higher than 1.25 .

\section{Competing Interests}

The authors declare that there are no competing interests regarding the publication of this paper.

\section{Acknowledgments}

The project presented in this paper is supported by the National Natural Science Foundation of China (Grants no. 41330641 and no. 51378118) and the Graduate Student Scientific Research Innovation Program of Jiangsu Province (no. CXLX13_111). The authors are also grateful to Professor Zhen-Shun Hong at Southeast University in China for his comments during the preparation of the paper.

\section{References}

[1] S. Leroueil, F. Tavenas, F. Brucy, P. La Rochelle, and M. Roy, "Behavior of destructured natural clays," ASCE Journal of the Geotechnical Engineering, vol. 105, no. 6, pp. 759-778, 1979.

[2] S. Leroueil and P. R. Vaughan, "The general and congruent effects of structure in natural soils and weak rocks," Géotechnique, vol. 40, no. 3, pp. 467-488, 1990.

[3] J. B. Burland, "On the compressibility and shear strength of natural clays,” Géotechnique, vol. 40, no. 3, pp. 329-378, 1990.

[4] Z. Hong and T. Tsuchida, "On compression characteristics of Ariake clays," Canadian Geotechnical Journal, vol. 36, no. 5, pp. 807-814, 1999.

[5] M. D. Liu and J. P. Carter, "Virgin compression of structured soils," Geotechnique, vol. 49, no. 1, pp. 43-57, 1999.

[6] M. D. Liu and J. P. Carter, "Modelling the destructuring of soils during virgin compression," Géotechnique, vol. 50, no. 4, pp. 479-483, 2000.

[7] Z.-S. Hong, L.-L. Zeng, Y.-J. Cui, Y.-Q. Cai, and C. Lin, "Compression behaviour of natural and reconstituted clays," Geotechnique, vol. 62, no. 4, pp. 291-301, 2012.

[8] H.-E. Low, K.-K. Phoon, T.-S. Tan, and S. Leroueil, "Effect of soil microstructure on the compressibility of natural Singapore marine clay," Canadian Geotechnical Journal, vol. 45, no. 2, pp. 161-176, 2008.

[9] M. D. Liu and J. P. Carter, "A structured Cam Clay model," Canadian Geotechnical Journal, vol. 39, no. 6, pp. 1313-1332, 2002.

[10] J. Suebsuk, S. Horpibulsuk, and M. D. Liu, "A critical state model for overconsolidated structured clays," Computers and Geotechnics, vol. 38, no. 5, pp. 648-658, 2011.
[11] J. Suebsuk, S. Horpibulsuk, and M. D. Liu, "Modified Structured Cam Clay: a generalised critical state model for destructured, naturally structured and artificially structured clays," Computers and Geotechnics, vol. 37, no. 7-8, pp. 956-968, 2010.

[12] T. Tsuchida and M. Gomyo, "Unified model of e-logp relationship with the consolidation of the effect of initial void ratio," in Proceedings of the International Symposium on Compression and Consolidation of Clayey Soils (IS-Hiroshima '95), pp. 379-384, Hiroshima, Japan, 1995.

[13] Z.-S. Hong, J. Yin, and Y.-J. Cui, "Compression behaviour of reconstituted soils at high initial water contents," Géotechnique, vol. 60, no. 9, pp. 691-700, 2010.

[14] A. B. Cerato and A. J. Lutenegger, "Determining intrinsic compressibility of fine-grained soils," ASCE Journal of Geotechnical and Geoenvironmental Engineering, vol. 130, no. 8, pp. 872-877, 2004.

[15] L.-L. Zeng, Z.-S. Hong, and Y.-J. Cui, "Determining the virgin compression lines of reconstituted clays at different initial water contents," Canadian Geotechnical Journal, vol. 52, no. 9, pp. 1408-1415, 2015.

[16] X. Bian, S. Qian, and J.-W. Ding, "Modeling virgin compression of reconstituted clay at different initial water contents," China Ocean Engineering, vol. 29, no. 5, pp. 745-755, 2015.

[17] M. Hattab, T. Hammad, J.-M. Fleureau, and P.-Y. Hicher, "Behaviour of a sensitive marine sediment: microstructural investigation," Géotechnique, vol. 63, no. 1, pp. 71-84, 2013.

[18] Y.-F. Deng, Y.-K. Wu, S.-Y. Liu, and Z.-S. Hong, "Sediment environment of shallow marine clays deposited in Lianyungang area and their physical and mechanical properties," Journal of Engineering Geology, vol. 13, no. 1, pp. 29-33, 2005 (Chinese).

[19] S. G. Chung, K. N. Prasad, T. S. Nagaraj, J. G. Chung, and K. Y. Jo, "Assessment of compressibility behavior of naturally cemented soft clays," Marine Georesources and Geotechnology, vol. 22, no. 1-2, pp. 1-20, 2004.

[20] H.-L. Liu and Z.-S. Hong, "Effect of sample disturbance on unconfined compression strength of natural marine clays," China Ocean Engineering, vol. 17, no. 3, pp. 407-416, 2003.

[21] Q. Li, C. W. Ng, and G. Liu, "Low secondary compressibility and shear strength of Shanghai Clay," Journal of Central South University, vol. 19, no. 8, pp. 2323-2332, 2012.

[22] S. Leroueil, M. Kabbaj, F. Tavenas, and R. Bouchard, "Stressstrain-strain rate relation for the compressibility of sensitive natural clays," Géotechnique, vol. 35, no. 2, pp. 159-180, 1985.

[23] X. Bian, The change law of sensitivity with stress level and its application in shield tunneling [Ph.D. thesis], Southeast University, Nanjing, China, 2014 (Chinese). 


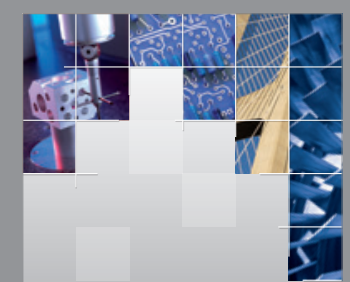

\section{Enfincering}
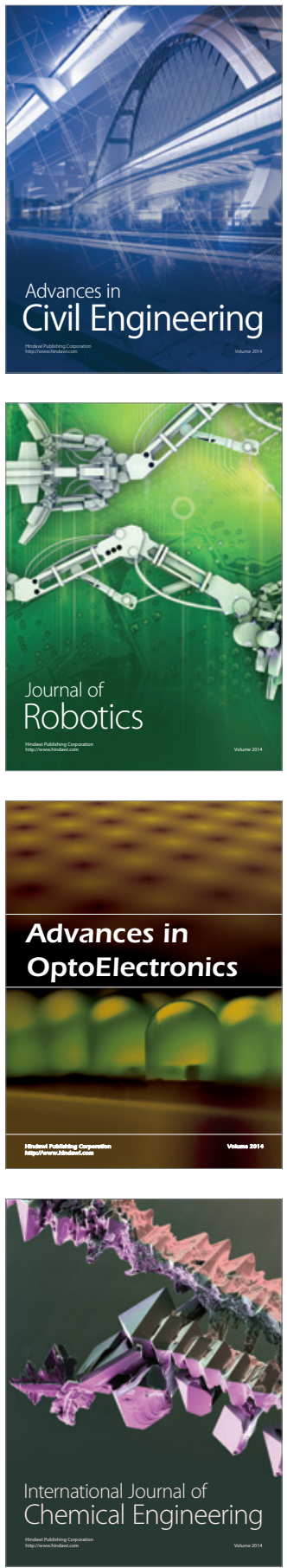

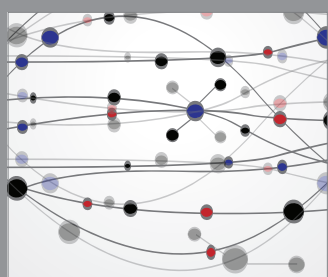

The Scientific World Journal

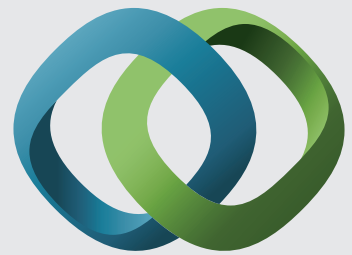

\section{Hindawi}

Submit your manuscripts at

http://www.hindawi.com
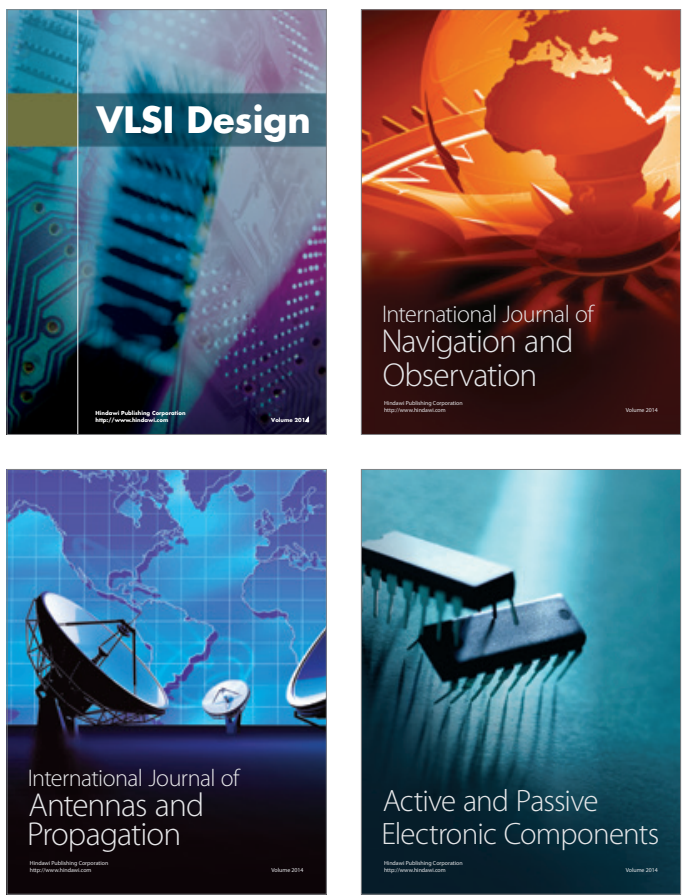
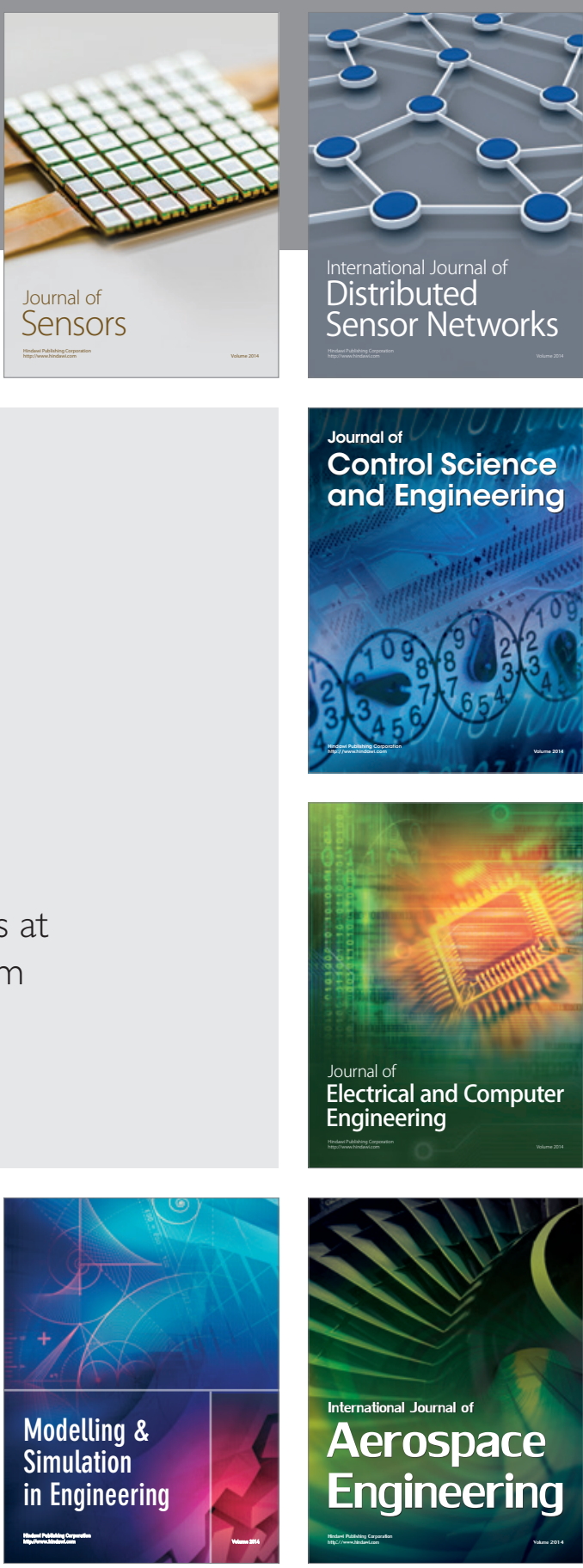

International Journal of

Distributed

Sensor Networks

Journal of

Control Science

and Engineering
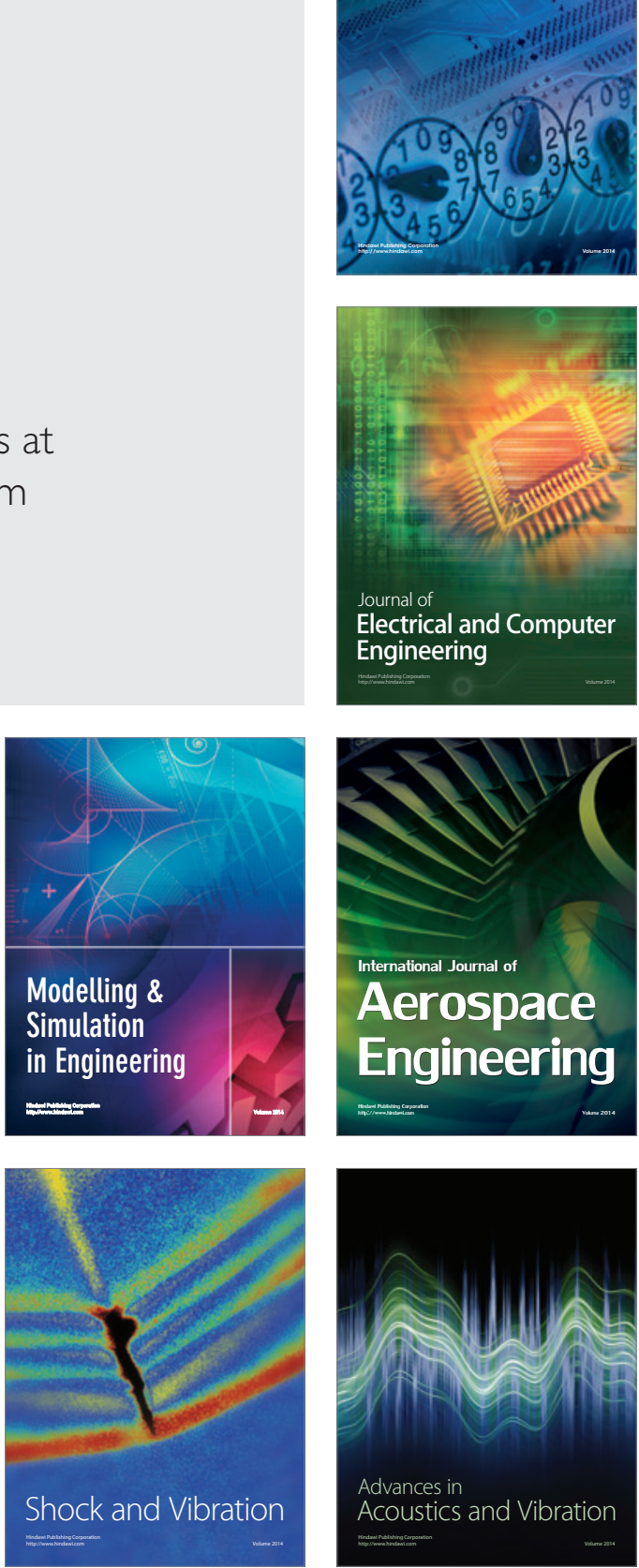